\title{
Growth of dense, hard yet low-stress Ti0.40Al0.27W0.33N nanocomposite films with rotating substrate and no external substrate heating
}

Zhengtao Wu, Olof Tengstrand, Babak Bakhit, Jun Lu, Joseph E Greene, Lars Hultman, Ivan Petrov and Grzegorz Greczynski

The self-archived postprint version of this journal article is available at Linköping University Institutional Repository (DiVA):

http://urn.kb.se/resolve?urn=urn:nbn:se:liu:diva-164373

N.B.: When citing this work, cite the original publication.

Wu, Z., Tengstrand, O., Bakhit, B., Lu, J., Greene, J. E, Hultman, L., Petrov, I., Greczynski, G., (2020), Growth of dense, hard yet low-stress Tio.40Alo.27Wo.33N nanocomposite films with rotating substrate and no external substrate heating, Journal of Vacuum Science \& Technology. A. Vacuum, Surfaces, and Films, 38(2), . https://doi.org/10.1116/1.5140357

Original publication available at:

https://doi.org/10.1116/1.5140357

Copyright: AIP Publishing http://www.aip.org/ 


\section{Growth of dense, hard yet low-stress $\mathrm{Ti}_{0.40} \mathrm{Al}_{0.27} \mathrm{~W}_{0.33} \mathrm{~N}$ nanocomposite films with rotating substrate and no external substrate heating}

Running title: Growth of dense, hard yet low-stress nanocomposite films using $\mathrm{W}^{+}$irradiation Running Authors: Zhengtao Wu et al.

Zhengtao Wu ${ }^{1, \text { a) }}$, Olof Tengstrand ${ }^{2}$, Babak Bakhit ${ }^{2}$, Jun Lu ${ }^{2}$, J.E. Greene 2, 3, 4, Lars Hultman ${ }^{2}$, Ivan Petrov ${ }^{2,3}$, and Grzegorz Greczynski ${ }^{2}$

${ }^{1}$ School of Electromechanical Engineering, Guangdong University of Technology, 510006 Guangzhou, China

${ }^{2}$ Thin Film Physics Division, Department of Physics, Linköping University, SE-581 83 Linköping, Sweden

${ }^{3}$ Frederick Seitz Materials Research Laboratory and Materials Science Department, University of Illinois, 104 South Goodwin, Urbana, Illinois 61801, USA

${ }^{4}$ Materials Science Department, National Taiwan University of Science and Technology, Taipei 10607, Taiwan

a) Electronic mail: wuzhengtao5@163.com

$\mathrm{W}^{+}$irradiation of TiAlN is used to demonstrate growth of dense, hard, and stress-free refractory nitride coatings with no external heating during reactive magnetron sputtering. $\mathrm{Ti}_{0.40} \mathrm{Al}_{0.27} \mathrm{~W}_{0.33} \mathrm{~N}$ nanocomposite films are deposited on $\mathrm{Si}(001)$ substrates using hybrid high-power impulse and dc magnetron co-sputtering (HiPIMS and DCMS) in an industrial sputtering system employing substrate rotation during film growth from six cathodes. Two $\mathrm{W}$ targets powered by HiPIMS, serve as a pulsed source of energetic $\mathrm{W}^{+}$ ions, with incident fluxes analyzed by in-situ time- and energy-resolved mass spectroscopy, while the remaining four targets (two elemental Ti targets and two Ti plates with Al plugs) are operated in DCMS mode (W-HiPIMS/TiAl-DCMS) to provide a continuous flux of metal atoms and sustain a high deposition rate. A negative substrate bias $V_{S}$ is applied only in synchronous with the $\mathrm{W}^{+}$-ion-rich portion of each HiPIMS pulse 
in order to provide film densification by heavy-ion irradiation of the TiAlN layers deposited between $\mathrm{W}^{+}$-ion exposures. $\mathrm{W}$ is selected for densification due to its high mass and relatively low reactivity with $\mathrm{N}_{2}$, thus minimizing target poisoning while enhancing gas rarefaction. Dense $\mathrm{Ti}_{0.40} \mathrm{Al}_{0.27} \mathrm{~W}_{0.33} \mathrm{~N}$ alloy films, grown with no external substrate heating (substrate temperature $T_{s}$ lower than $150{ }^{\circ} \mathrm{C}$ due to heat load from the plasma) and $V_{s}=500 \mathrm{~V}$, exhibit a nanoindentation hardness of $H=23.1 \mathrm{GPa}$ and an elastic modulus of $E=378 \mathrm{GPa}$, which are, respectively, $210 \%$ and $40 \%$ higher than for reference underdense DCMS $\operatorname{Ti}_{0.58} \mathrm{Al}_{0.42} \mathrm{~N}$ films grown under the same conditions, but without $\mathrm{W}^{+}$irradiation. The $\mathrm{W}$ ion bombardment does not affect the film stress state, which is compressive and low at $1.2 \mathrm{GPa}$.

\section{INTRODUCTION}

The growth of dense thin films by magnetron sputtering under a noble-gas-based plasma condition, typically requires elevated substrate temperatures $T_{s}$ to ensure sufficient adatom mobilities. ${ }^{1}$ Films grown with no external substrate heating are columnar and underdense, as demonstrated by open inter- and intra-columnar voids visible in cross-sectional transmission electron microscopy images and by X-ray reflectivity results..$^{2-5}$ Thus, these layers exhibit low nanoindentation hardness and elastic modulus values. Applying ion bombardment during film growth is often used to enhance densification by providing continuous near-surface ion mixing and enhancing adatom mean-free paths. ${ }^{6,7}$ However, this generally leads to trapping of noble-gas ions, as well as recoiled surface atoms in interstitial sites, which, in turn, results in high compressive stress. $^{8}$ 
Recently, we presented a novel approach for the growth of dense, hard, yet low stressed thin films with no external substrate heating. ${ }^{9-10}$ In those experiments, TiN was used as a model materials system and we employed hybrid high-power impulse and dc magnetron co-sputtering (HiPIMS/DCMS) ${ }^{11}$ to grow $\mathrm{Ti}_{0.92} \mathrm{Ta}_{0.08} \mathrm{~N}$ and $\mathrm{Ti}_{0.41} \mathrm{Al}_{0.51} \mathrm{Ta}_{0.08} \mathrm{~N}$ films. The Ta target was powered by HiPIMS and served as a pulsed source of heavy Ta ions, while a high deposition rate was sustained by a continuous flux of Ti or Ti and $\mathrm{Al}$ atoms from DCMS-driven targets. A substrate bias was applied in synchronous with the metal-ion-rich portion of the Ta-HiPIMS pulse. ${ }^{12} \mathrm{We}$ demonstrated that tuning the incident $\mathrm{Ta}^{+}$energy by varying the $V_{s}$ amplitude provides means of controlling film density and allows for effective elimination of both inter- and intra-columnar porosity characteristic for films grown with no external substrate heating. Nanoindentation hardness $H$ and elastic modulus $E$ of $\mathrm{Ti}_{0.92} \mathrm{Ta}_{0.08} \mathrm{~N}$ films exhibited a strong dependence on the incident energy of $\mathrm{Ta}^{+}$ions, controlled by the pulsed substrate bias $V_{s} . H$ varied from 14.4 GPa at $V_{s}=-20 \mathrm{~V}$ to $26.1 \mathrm{GPa}$ at $V_{s}=-160 \mathrm{~V}$, while $E$ increased from 345 to 497 GPa. These values were compared with $H=7.8 \mathrm{GPa}$ and $E=248 \mathrm{GPa}$ obtained for DCMS TiN reference layers grown with no external substrate heating. The use of highmass-metal ion-irradiation was shown to be essential for densification and obtaining superior mechanical properties. Lower-mass $\mathrm{Ti}^{+}$-ion irradiation with the same flux and ion energy had a minimal effect. Fully-dense $\operatorname{Ti}_{0.92} \mathrm{Ta}_{0.08} \mathrm{~N}$ layers grown with no external heating perform well as diffusion barriers between $\mathrm{Cu}$ metallization layers and $\mathrm{Si}(001)$ substrates. ${ }^{13}$

The above experiments were carried out using a stationary sputtering configuration in which the position of each substrate was fixed with respect to the targets 
during film growth. This approach provided the means to investigate the basic phenomena and revealed mechanisms responsible for film densification. However, requirement of precise control over metal-ion times-of-flight from the target to the substrate implies significant challenges for industrial implementations of metal-ion synchronized HiPIMS/DCMS growth scenario due to the fact that in the typical setup the target-to-substrate distance varies continuously, while substrates rotate in the planetary motion scheme in front of several sputtering sources. Thus, substrates are exposed to the energetic metal-ion flux only for a short fraction of the total deposition time, when they pass in front of the HiPIMS-operated magnetron, which is very different from the experiments conducted in the stationary configuration described above.

Here, we investigate densification effects due to heavy-metal ion-irradiation under more typical industrial conditions, that is, in a multi-cathode configuration with the substrate rotating in front of six targets during film growth. $\operatorname{Ti}_{1-x} \mathrm{Al}_{\mathrm{x}} \mathrm{N}$, a widely used wear-protective layer on cutting tools, exhibiting both high hardness and excellent hightemperature oxidation resistance, is used as a model material system. $\mathrm{W}^{+}$irradiation is selected based on previous ion mass spectrometry studies performed at the substrate position, which showed severe Ar rarefaction during HiPIMS pulses, while sputtering in $\mathrm{Ar} / \mathrm{N}_{2}$ gas mixtures to such extent that the time- and energy-integrated metal/gas ion ratio during W-HiPIMS pulse was $\sim 100 .{ }^{14-15}$ Such conditions imply large flexibility in the choice of bias pulse offset and pulse length as both $\mathrm{Ar}^{+}$and $\mathrm{N}_{2}{ }^{+}$ion fluxes are essentially eliminated during the time period of several hundred $\mu$ s following the ignition of the HiPIMS pulse. This allows efficient $\mathrm{W}^{+}$irradiation of the growing film surface, while minimizing $\mathrm{Ar}^{+}$incorporation, even when the substrate-target separation is continuously 
changing during substrate rotation, by using relatively long bias pulses. $\operatorname{Ti}_{1-\mathrm{x}-\mathrm{y}} \mathrm{Al}_{\mathrm{x}} \mathrm{W}_{\mathrm{y}} \mathrm{N}$ alloy films deposited with $T_{s} \leq 150{ }^{\circ} \mathrm{C}$ (due to plasma heating) exhibit hardness and elastic modulus values which are comparable to those obtained for layers grown at high temperatures $\left(400-500^{\circ} \mathrm{C}\right) .{ }^{16-18}$

\section{EXPERIMENTAL}

$\mathrm{Ti}_{1-\mathrm{x}-\mathrm{y}} \mathrm{Al}_{\mathrm{x}} \mathrm{W}_{\mathrm{y}} \mathrm{N}$ and $\mathrm{Ti}_{1-\mathrm{x}} \mathrm{Al}_{\mathrm{x}} \mathrm{N}$ films are grown in a CC800/9 CemeCon $\mathrm{AG}$ magnetron sputtering system equipped with six cast rectangular $8.8 \times 50 \mathrm{~cm}^{2}$ targets. The target configuration, shown schematically in Fig. 1, includes two-each elemental Ti and W targets together with two TiAl targets consisting of Ti plates with 60 pieces of $1-\mathrm{cm}-$ diameter $\mathrm{Al}$ plugs distributed along the racetrack. $\mathrm{Si}(001)$ substrates, $3 \times 1 \mathrm{~cm}^{2}$, are mounted on a substrate table which rotates sequentially under all targets at three revolutions per minute. As a result, the target-to-substrate distance varies continuously during film growth with the lower limit of $7.5 \mathrm{~cm}$. The system base pressure is $3.8 \times 10^{-7}$ Torr $(0.05 \mathrm{mPa})$.

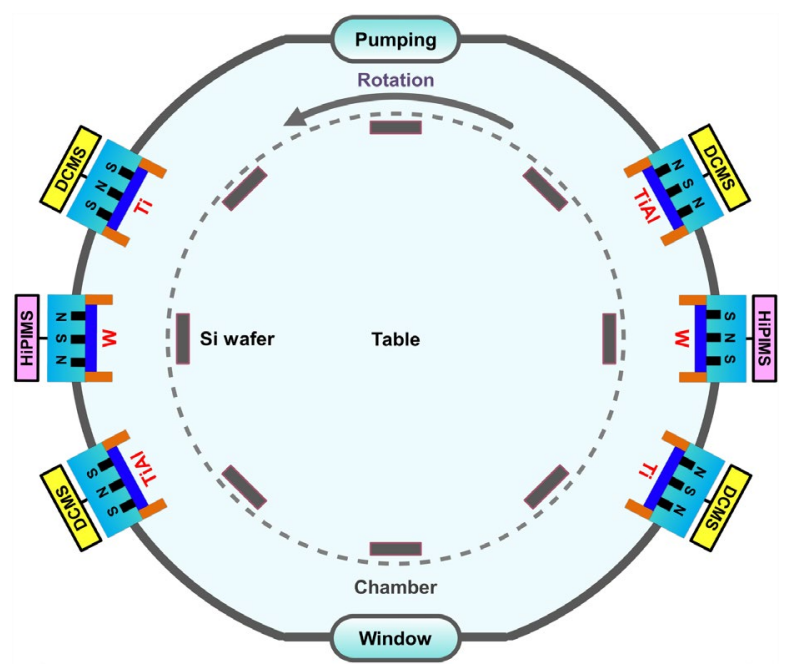

Fig. 1. Schematic diagram of HiPIMS/DCMS co-sputtering deposition system for TiAlWN film. 
The substrates are cleaned sequentially in acetone and isopropyl alcohol and mounted with clips such that their long axis is parallel to the long axis of the targets. Prior to film growth, the system is degassed using two resistive heaters, each operated at 1.5 $\mathrm{kW}$ for $0.5 \mathrm{~h}$, resulting in a temperature of $150{ }^{\circ} \mathrm{C}$ at the substrate position. The power is then switched off and $T_{S}$ is allowed to decrease to $\sim 120{ }^{\circ} \mathrm{C}$ prior to initiating films growth. No external substrate heating is applied during deposition and $T_{s}$, monitored with a calibrated thermocouple bonded to a dummy substrate, asymptotically reaches a maximum of $\sim 150{ }^{\circ} \mathrm{C}$ due to plasma heating during $40 \mathrm{~min}$ film deposition. The Ar flow is set at $350 \mathrm{sccm}$, while the $\mathrm{N}_{2}$ flow is controlled by an automatic pressure regulator via a feedback loop to maintain the total pressure constant during deposition at 3 mTorr $(0.4$ $\mathrm{Pa})$.

A hybrid target power scheme is employed in which the two magnetrons equipped with $\mathrm{W}$ targets are operated in HiPIMS mode, while the other four are operated as conventional de magnetrons. The average power to each W-HiPIMS target is $1.0 \mathrm{~kW}$ (10 $\mathrm{J} /$ pulse, $100 \mathrm{~Hz}, 110 \mu \mathrm{s}$ pulse length) resulting in peak target current densities of $\sim 0.5$ $\mathrm{A} / \mathrm{cm}^{2}$. The DCMS power is $2.0 \mathrm{~kW}$ for each target. During growth of reference TiAlN layers, only the four DC-powered targets are used. For all film growth experiments, the deposition time is constant at $40 \mathrm{~min}$.

A pulsed substrate bias $V_{s}=-500 \mathrm{~V}$ is applied synchronously with $110-\mu$ sHiPIMS pulses, based upon time- and energy-resolved mass spectroscopy analyses performed at the substrate position, which revealed the time- and energy-integrated $\mathrm{W}^{+} /\left(\mathrm{Ar}^{+}+\mathrm{N}_{2}^{+}\right)$ion ratio during W-HiPIMS pulse as high as $\sim 100 .{ }^{15}$ The bias offset is set 
at $20 \mu \mathrm{s}$, which corresponds to the transit time for most energetic $\mathrm{W}^{+}$ions at the shortest target-substrate separation. The bias pulse length is set at the maximum available value of $200 \mu$ s to ensure energetic $\mathrm{W}^{+}$bombardment even at the longest target-substrate distance. $V_{s}$ is intentionally selected at a high value in order to extend the $\mathrm{W}^{+}$penetration range throughout the TiAlN layers grown during the time when the substrate is passing in front of the DCMS targets (see Fig. 1). At all other times, the substrate is at floating potential. The offset time accounts for the average metal-ion time-of-flight to the substrate.

Ion-energy distribution functions (IEDFs) $I_{\mathrm{w}^{n+}}\left(E_{i}\right)$ are recorded in HiPIMS mode for $\mathrm{W}^{n+}(n=1,2, \ldots)$ and gas ions during 100 consecutive pulses such that the total acquisition time per data point is $1 \mathrm{~ms}$. The ion energy is scanned in $0.5 \mathrm{eV}$ steps from $E_{i}$ $=1$ to $80 \mathrm{eV}$. In order to obtain the plasma composition at the substrate plane, where the orifice of the mass spectrometer is positioned, rather than at the detector, data are corrected for ion times-of-flight through the instrument using the approach described in Ref. 19. Additional details regarding the IEDFs measurements are given in Ref. 20.

Film compositions are determined via Rutherford backscattering spectrometry (RBS) and times-of-flight elastic recoil detection analysis (ToF-ERDA) carried out in a 5-MV NEC-5SDH-2 pelletron tandem accelerator. For RBS, 2-MeV ${ }^{4} \mathrm{He}^{+}$ions incident at $45^{\circ}$ with respect to the sample surface normal are detected at a scattering angle of $170^{\circ}$. ToF-ERDA results are detected at a $45^{\circ}$ angle between the $36-\mathrm{MeV}^{127} \mathrm{I}^{8+}$ primary beam incident at $67.5^{\circ}$ and a gas ionization chamber detector. Elemental depth profiles are acquired from ToF-ERDA time and energy coincidence spectra using the software packages. The stopping power data required for both RBS and ERDA simulations are retrieved from an open access software, SRIM 2013. 
Ti 2p, Al 2p, N 1s, and W 4f core-level X-ray photoelectron spectroscopy (XPS) spectra are acquired in a Kratos Axis Ultra DLD instrument with a base pressure of $1.1 \times 10^{-9}$ Torr $\left(1.5 \times 10^{-7} \mathrm{~Pa}\right)$. Monochromatic $\mathrm{Al} K_{\alpha}$ radiation $(h v=1486.6 \mathrm{eV})$ is used with an anode power of $150 \mathrm{~W}$. All spectra are collected orthogonal to the sample surface. In order to avoid uncertainties related to using the $\mathrm{C} 1 \mathrm{~s}$ signal from adventitious carbon as the energy reference, ${ }^{21}$ the binding energy (BE) scale is referenced to the Fermi energy cut-off of a sputter-cleaned polycrystalline Ag film, resulting in an $\mathrm{Ag} 3 \mathrm{~d}_{5 / 2}$ peak position of $368.3 \mathrm{eV}$. The analyzer pass energy is set to $20 \mathrm{eV}$, which yields a full-width at half maximum intensity of $0.55 \mathrm{eV}$ for the $\mathrm{Ag} 3 \mathrm{~d}_{5 / 2}$ peak. Prior to spectra acquisition, all surfaces are sputter-etched for two minutes with $4.0 \mathrm{keV} \mathrm{Ar}^{+}$ions, incident at an angle of $70^{\circ}$ with respect to the sample normal, while the beam is rastered over a $3 \times 3 \mathrm{~mm}^{2}$ area. The $\mathrm{Ar}^{+}$ion energy is then lowered to $0.5 \mathrm{keV}$ for another $10 \mathrm{~min}$ to minimize the influence of beam effects on core-level spectra. ${ }^{22-24}$ The area analyzed by XPS is $0.3 \times 0.7$ $\mathrm{mm}^{2}$ and centered in the middle of the ion-etched crater. Spectra deconvolution and quantification is performed using the Casa XPS software package and sensitivity factors supplied by the instrument manufacturer.

$\theta-2 \theta$ X-ray diffraction (XRD) scans and $\sin ^{2} \psi$ analyses for residual stress $\sigma_{r e}$ determinations are carried out. ${ }^{25}$ Three sets of $\sin ^{2} \psi$ measurements on different areas of the samples are performed to obtain the average residual stress values and deviations. With the $\sin ^{2} \psi$ technique, film strain $\varepsilon$ is evaluated by measuring the position of a Bragg reflection to obtain the corresponding film interplanar spacing $d$ as a function of the tilt angle $\psi$ between the sample normal and the scattering plane defined by the incoming and diffracted X-ray beams. The film strain $\varepsilon$ as a function of the tilt angle $\psi$, defined with 
respect to the substrate normal, is equal to the normalized difference between $d$ and the relaxed interplanar spacing $d_{0}$,

$$
\varepsilon(\psi)=\frac{d-d_{0}}{d_{0}},
$$

Measured $\varepsilon(\psi)$ values are used to determine the residual stress $\sigma_{r e}$ through Hooke's law of linear elasticity as:

$$
\varepsilon(\psi)=\frac{1+v}{E} \sigma_{r e} \sin ^{2} \psi-\frac{2 v}{E} \sigma_{r e}
$$

in which $v$ is the Poisson ratio. Experimentally, the in-plane stress is extracted from the slope of $\varepsilon(\psi)$ vs. $\sin ^{2} \psi$. Tilt angles $\psi$ are set to $0^{\circ}, 18.4^{\circ}, 26.6^{\circ}, 33.2^{\circ}, 39.2^{\circ}, 45.0^{\circ}, 50.8^{\circ}$, $56.8^{\circ}, 63.4^{\circ}$, and $71.6^{\circ}$, corresponding to $\sin ^{2} \Psi$ values of $0,0.1,0.2,0.3,0.4,0.5,0.6,0.7$, 0.8 , and 0.9 , respectively. Relaxed TiAlWN lattice constants $a_{0}$ are determined from $\theta-2 \theta$ scans acquired at the strain-free tilt angle $\psi^{*}$, defined by setting $\varepsilon=0$ in Eq. (2):

$$
\psi^{*}=\arcsin \left(\sqrt{\frac{2 v}{1+v}}\right)
$$

Here, we use $v=0.19$ for cubic TiAlN and TiAlWN which yields $\psi^{*}=34.4^{\circ} .^{26}$

Plan-view transmission electron microscopy (TEM) and cross-sectional TEM (XTEM) specimens are prepared by mechanical polishing, followed by $\mathrm{Ar}^{+}$ion milling at $5 \mathrm{kV}$ with an $8^{\circ}$ incidence angle and sample rotation. During the final thinning stages, the ion energy and incidence angle are reduced to $2.5 \mathrm{kV}$ and $5^{\circ}$. Film microstructure is analyzed in a FEI Tecnai $\mathrm{G}^{2}$ TF 20 UT transmission electron microscope operated at 200 $\mathrm{kV}$.

Nanoindentation measurements are performed in an IBIS nanoindenter equipped with a sharp Berkovich diamond probe calibrated using a fused silica reference sample. A 
minimum of 25 indents is made in each specimen with maximum loads of $15 \mathrm{mN}$ and indentation depths not exceeding $10 \%$ of the film thickness in order to minimize substrate effects. Film hardness $H$ and elastic modulus $E$ are determined using the method described by Oliver and Pharr. ${ }^{27}$

\section{RESULTS AND DISCUSSION}

\section{A. Result}

Fig. 2 shows $\mathrm{W}^{+}, \mathrm{W}^{2+}, \mathrm{Ar}^{+}, \mathrm{N}_{2}{ }^{+}$, and $\mathrm{N}^{+}$IEDFs at the substrate plane during 300$\mu$ s time intervals, beginning with the ignition of $110 \mu$ s HiPIMS pulses, while sputtering a $\mathrm{W}$ target in $\mathrm{Ar} / \mathrm{N}_{2}$ at a peak current density $J_{t, \text { peak }}=\sim 0.5 \mathrm{~A} / \mathrm{cm}^{2}$. Metal IEDFs exhibit broad Sigmund-Thompson type sputtered-species energy distributions, with high-energy tails extending up to $80 \mathrm{eV}$ and beyond. ${ }^{28-29}$ This indicates that the sputter-ejected atoms undergo few collisions between the target and substrate plane due to highly-efficient plasma rarefaction. ${ }^{30}$ The effect is particularly strong for $\mathrm{W}$ due to its high-mass $\left(m_{\mathrm{W}}=\right.$ $183.84 \mathrm{amu}$ ), high self-sputter yield,,$^{31-32}$ and low nitride heat of formation $\Delta H_{m}^{\Theta}=-0.2$ $\mathrm{eV} /$ atom $(-3.4 \mathrm{eV} / \text { atom for } \mathrm{TiN})^{33}$ which minimizes target poisoning and results in a high temporal flux of sputter-ejected atoms in reactive mode. 


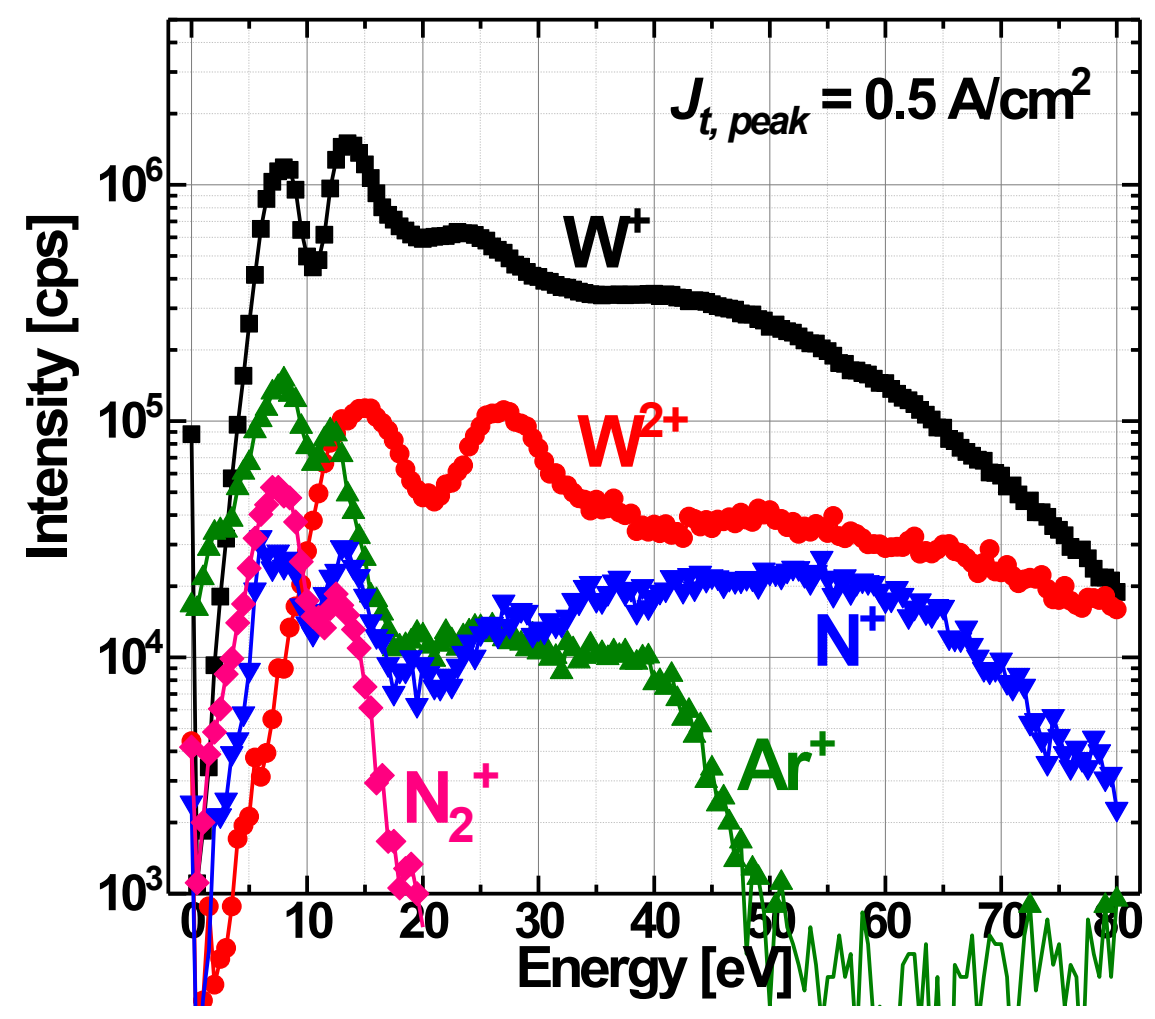

Fig. 2. Ion energy distribution functions (IEDFs) from $\mathrm{W}$ target operated in HiPIMS mode. For HiPIMS, the IEDFs correspond to a peak target current density of 0.5 $\mathrm{A} / \mathrm{cm}^{2}$.

Thermalized IEDF peaks, typically observed for Group IVb TMs, are absent in Fig. 2, not only for metal ions, but also for both $\mathrm{Ar}^{+}$and $\mathrm{N}_{2}{ }^{+} . I_{N^{+}}\left(E_{i}\right)$ differs significantly from $I_{N_{2}^{+}}\left(E_{i}\right)$, and closely follows the shape of $\mathrm{W}^{+}$IEDFs. This indicates that $\mathrm{N}^{+}$ions originate from the target, in agreement with previous reports. ${ }^{13}$ The source of $\mathrm{N}^{+}$is a combination of sputter-ejected $\mathrm{N}$ atoms and reflected $\mathrm{N}$ atoms arising from dissociative $\mathrm{N}_{2}{ }^{+}$collisions at the target surface. The $\mathrm{W}^{2+}$ flux accounts for only $3 \%$ of the total metalion flux, due to the second ionization potential of $\mathrm{W}\left(I P_{W}^{2}=17.68 \mathrm{eV}\right)$ being higher than the first ionization potential of $\operatorname{Ar}\left(I P_{A \mathrm{r}}^{1}=15.75 \mathrm{eV}\right),{ }^{34}$ the primary sputtering gas. The 
strong dominance of the singly-charged $\mathrm{W}$ ion over gas-ion irradiation is highly beneficial as it allows for more precise control over the incident energy of metal-ions without affecting $\mathrm{Ar}^{+}$and $\mathrm{N}_{2}{ }^{+}$ion energy.

Fig. 3 shows time-dependent intensities of energy-integrated primary-ion fluxes $\mathrm{W}^{+}, \mathrm{W}^{2+}, \mathrm{Ar}^{+}, \mathrm{N}_{2}^{+}$, and $\mathrm{N}^{+}$, recorded while reactively sputtering a $\mathrm{W}$ target in $\mathrm{Ar} / \mathrm{N}_{2}$ with $J_{t, p e a k}=\sim 0.5 \mathrm{~A} / \mathrm{cm}^{2}$. Results are plotted with a $10-\mu$ s resolution. Zero on the time axis corresponds to the onset of the cathode voltage pulse; each data point at time $t$ represents the number of ions collected during the interval from $t-5$ to $t+5 \mu \mathrm{s}$. The energy and timeintegrated metal/gas ion ratio $N_{W^{+}} / N_{g^{+}}$, defined as $\int F_{W^{+}}(t) d t / F_{g^{+}}(t) d t$ (in which $F_{W^{+}}(t)$ is the metal-ion flux and $F_{g^{+}}(t)$ is the total gas-ion flux including $\mathrm{Ar}^{+}, \mathrm{N}_{2}{ }^{+}$, and $\mathrm{N}^{+}$) with the integral extending between $t=0$ and $300 \mu \mathrm{s}$, is $\sim 38$. Since a lower peak target current density $\left(J_{t, \text { peak }}=\sim 0.5 \mathrm{~A} / \mathrm{cm}^{2}\right)$ is used in the present work, resulting in a lower metal/gas ion ratio compared to the approach described in Ref. 15 , i.e. $J_{t, p e a k}=1.0$ $\mathrm{A} / \mathrm{cm}^{2}$. The high value is due to strong gas-rarefaction effects, which scale with increasing metal/gas atom mass ratio. That is, the metal/gas collision cross-section increases with increasing sputtered atom mass, resulting in shorter metal-atom mean free paths, increased momentum transfer, and hence more effective gas heating. 


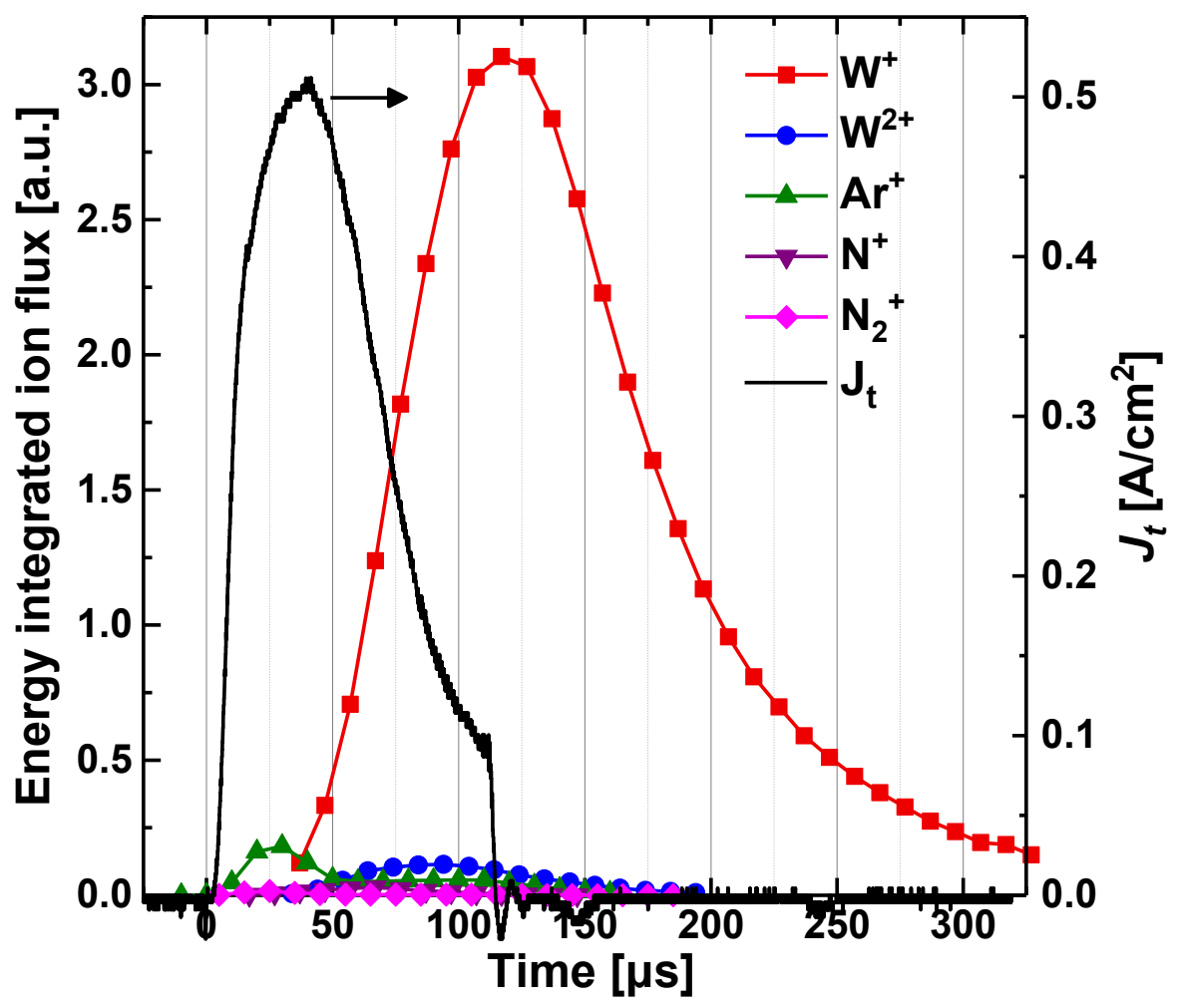

Fig. 3. Time evolution of the energy-integrated $\mathrm{W}^{+}, \mathrm{W}^{2+}, \mathrm{N}^{+}, \mathrm{N}_{2}{ }^{+}$, and $\mathrm{Ar}^{+}$ion fluxes incident at the substrate plane during and after HiPIMS pulses while sputtering a $\mathrm{W}$ target in Ar at $0.4 \mathrm{~Pa}(3 \mathrm{mTorr})$ with $100 \mu$ s HiPIMS pulses. The peak target current density $J_{t, \text { peak }}$ is maintained constant at $\sim 0.5 \mathrm{~A} / \mathrm{cm}^{2}$. Target current pulse $J_{t}$, shown in black line, are scaled to match the ion fluxes in order to facilitate comparison.

An independent evidence for severe rarefaction during W-HiPIMS sputtering in $\mathrm{Ar} / \mathrm{N}_{2}$ gas mixtures is presented in Fig. 4 showing time-resolved $I_{W^{+}}\left(E_{i}\right)$ IEDFs recorded during consecutive $50 \mu$ s time intervals throughout, and following $110 \mu$ s HiPIMS pulses. Clearly, $I_{W^{+}}\left(E_{i}\right)$ IEDFs are preserved throughout the entire measurement period up to $370 \mu$ s, i.e., they do not collapse into low-energy thermalized peaks. Instead, there is a 
gradual loss in intensity and even ions arriving after the HiPIMS pulse, $t \geq 110 \mu \mathrm{s}$, have an average energy that is significantly higher than thermal.

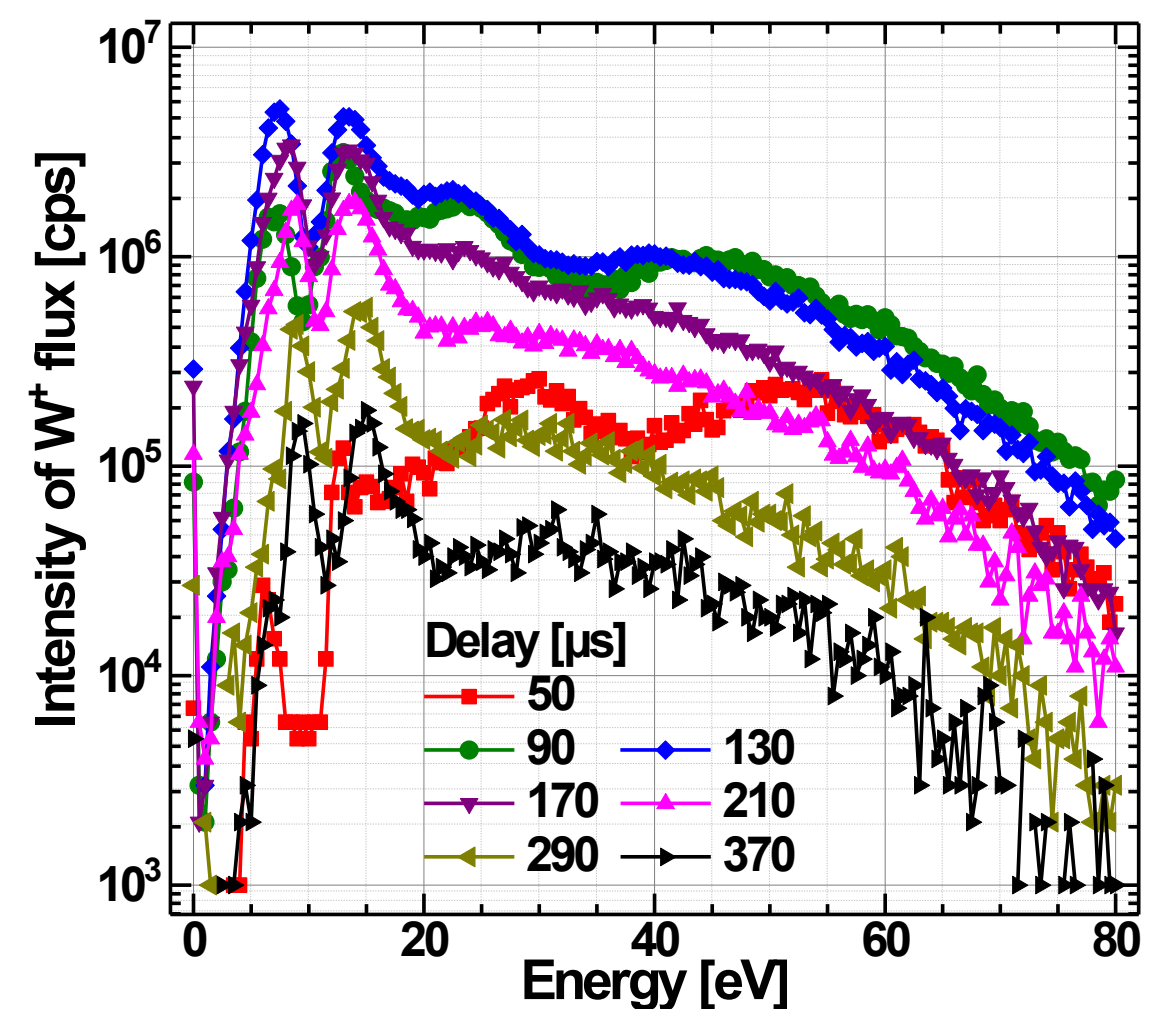

Fig. 4. (Color online) $\mathrm{W}^{+}$IEDFs acquired with $100 \mu$ s pulses, during HiPIMS sputtering of a W target in $\mathrm{Ar}$ at $0.4 \mathrm{~Pa}(3 \mathrm{mTorr})$. The target power is $1 \mathrm{~kW}$ with a 100 $\mathrm{Hz}$ pulse frequency. Times indicated in the legends correspond to the number of microseconds from the onset of the HiPIMS pulse at which the IEDF was acquired.

Low gas-ion fluxes during HiPIMS pulses make $\mathrm{W}$ an ideal candidate for the present experiments involving substrate rotation under targets with different targetsubstrate separations since precise synchronization of the bias pulse to the metal-ion-rich portion of the ion flux at the substrate is not necessary. Instead, relatively long bias pulses 
(200 $\mu$ s) can be used to efficiently densify the growing film without risking significant Ar implantation.

The average composition of the films determined by a combination of ToF-ERDA and RBS analyses is $\mathrm{Ti}_{0.58} \mathrm{Al}_{0.42} \mathrm{~N}$ for the DCMS reference sample and $\mathrm{Ti}_{0.40} \mathrm{Al}_{0.27} \mathrm{~W}_{0.33} \mathrm{~N}$ for the alloy films deposited by the hybrid HiPIMS/DCMS technique. Argon concentrations are 0.4 and 1.3 at. $\%$ for $\mathrm{Ti}_{0.58} \mathrm{Al}_{0.42} \mathrm{~N}$ and $\mathrm{Ti}_{0.40} \mathrm{Al}_{0.27} \mathrm{~W}_{0.33} \mathrm{~N}$, respectively, with oxygen concentrations of 7.8 and 1.0 at. $\%$. RBS also provides the areal density $n_{b} \cdot t$ of metal atoms, where $n_{b}$ is the bulk density $\left[\mathrm{at} / \mathrm{cm}^{3}\right]$ and $t$ is the film thickness $[\mathrm{cm}]$. The results are given in Table 1. As a result of $\mathrm{W}^{+}$ion irradiation, $\mathrm{Ti}$ and $\mathrm{Al}$ area densities decrease by $2.3 \%$ and $10.3 \%$ from $\mathrm{Ti}_{0.58} \mathrm{Al}_{0.42} \mathrm{~N}$ to $\mathrm{Ti}_{0.40} \mathrm{Al}_{0.27} \mathrm{~W}_{0.33} \mathrm{~N}$, respectively, indicating a larger resputtering rate for the lighter $\mathrm{Al}$ atoms compared to that of $\mathrm{Ti}$.

TABLE 1. Area density of metal atoms in films determined by RBS.

\begin{tabular}{lccc}
\hline \hline Samples & \multicolumn{3}{l}{ Areal density of metal atoms $\left[10^{18} \mathrm{at} / \mathrm{cm}^{2}\right]$} \\
& $\mathrm{Ti}$ & $\mathrm{Al}$ & $\mathrm{W}$ \\
\hline $\mathrm{Ti}_{0.58} \mathrm{Al}_{0.42} \mathrm{~N}$ & 1.750 & 1.265 & - \\
$\mathrm{Ti}_{0.40} \mathrm{Al}_{0.27} \mathrm{~W}_{0.33} \mathrm{~N}$ & 1.710 & 1.135 & 1.410 \\
\hline \hline
\end{tabular}

Fig. 5 shows $\theta-2 \theta$ scans recorded as a function of the tilt angle $\psi$ for (a) $\mathrm{Ti}_{0.58} \mathrm{Al}_{0.42} \mathrm{~N}$ and (b) $\mathrm{Ti}_{0.40} \mathrm{Al}_{0.27} \mathrm{~W}_{0.33} \mathrm{~N}$ films. In both cases, the only reflections detected in the $2 \theta$ range from $30^{\circ}$ to $50^{\circ}$ are $\mathrm{NaCl}$ structure 111 and $002 \mathrm{TiN}$ peaks, consistent with single-phase films. The $\mathrm{Ti}_{0.58} \mathrm{Al}_{0.42} \mathrm{~N}$ layer (Fig. 5(a)) has a strong 111 texture. The residual stress $\sigma$ obtained from $\sin ^{2} \psi$ analyses is -1.1 GPa. For the $\operatorname{Ti}_{0.40} \mathrm{Al}_{0.27} \mathrm{~W}_{0.33} \mathrm{~N}$ film grown with $\mathrm{W}^{+}$ion irradiation (Fig. 5(b)), the peaks are broader than for the reference 
$\mathrm{Ti}_{0.58} \mathrm{Al}_{0.42} \mathrm{~N}$ sample indicating a decreased grain size due to the heavy-ion bombardment. ${ }^{13}$ The film has a slight 002 texture and the residual stress is $-1.2 \mathrm{GPa}$, essentially the same as that of the reference layer grown without $\mathrm{W}^{+}$bombardment. The relaxed lattice parameters $a_{0}$ of $\operatorname{Ti}_{0.58} \mathrm{Al}_{0.42} \mathrm{~N}$ and $\mathrm{Ti}_{0.40} \mathrm{Al}_{0.27} \mathrm{~W}_{0.33} \mathrm{~N}$ films are calculated 4.195 and $4.242 \AA$, respectively.
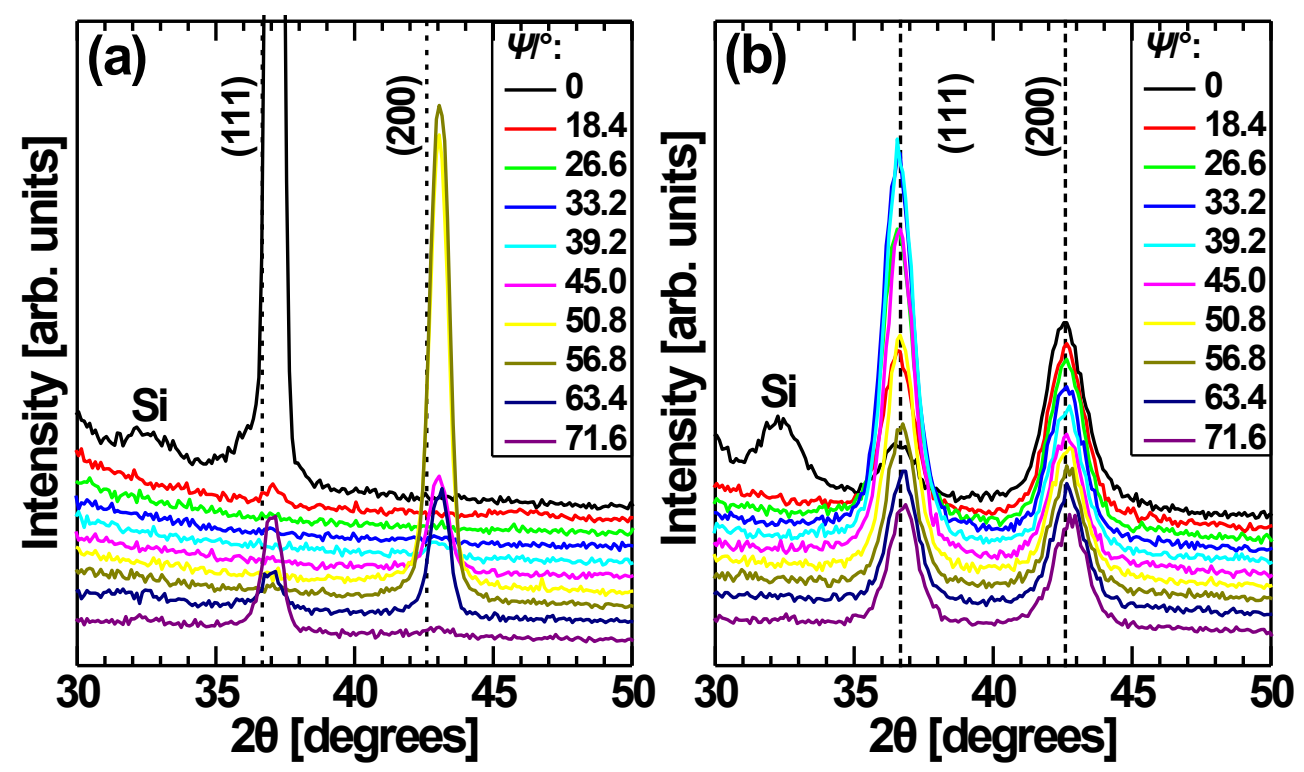

Fig. 5. $\theta-2 \theta$ scanning patterns at different tilt angles $\Psi$ for (a) $\mathrm{Ti}_{0.58} \mathrm{Al}_{0.42} \mathrm{~N}$ and (b) $\mathrm{Ti}_{0.40} \mathrm{Al}_{0.27} \mathrm{~W}_{0.33} \mathrm{~N}$ films. The reference marked by dashed lines is TiN (JCPDS No. 38 1420).

Fig. 6 presents XTEM overview images of (a) $\mathrm{Ti}_{0.58} \mathrm{Al}_{0.42} \mathrm{~N}$ and (b) $\operatorname{Ti}_{0.40} \mathrm{Al}_{0.27} \mathrm{~W}_{0.33} \mathrm{~N}$ films together with higher magnification insets of the top portions of both films. The thickness of the $\mathrm{Ti}_{0.58} \mathrm{Al}_{0.42} \mathrm{~N}$ layer is $\sim 0.76 \mu \mathrm{m}$. The film has a columnar structure with facetted column tops. The low deposition temperature $\left(T_{s} / T_{m} \leq 0.14\right)$, hence low adatom mobility, results in a columnar porosity best seen in the inset of Fig. 6(a). $\operatorname{Ti}_{0.40} \mathrm{Al}_{0.27} \mathrm{~W}_{0.33} \mathrm{~N}$ layer is thicker, $\sim 0.94 \mu \mathrm{m}$, due to the additional flux from the two 
$\mathrm{W}$ targets. The effects of $\mathrm{W}^{+}$ion irradiation are clear in Fig. 6(b): the average column width increases from $35 \pm 4 \mathrm{~nm}$ for the reference $\mathrm{Ti}_{0.58} \mathrm{Al}_{0.42} \mathrm{~N}$ to $85 \pm 10 \mathrm{~nm}$ for $\mathrm{Ti}_{0.40} \mathrm{Al}_{0.27} \mathrm{~W}_{0.33} \mathrm{~N}$, columnar porosity disappears, and the column tops become rounded with much shallower groves.
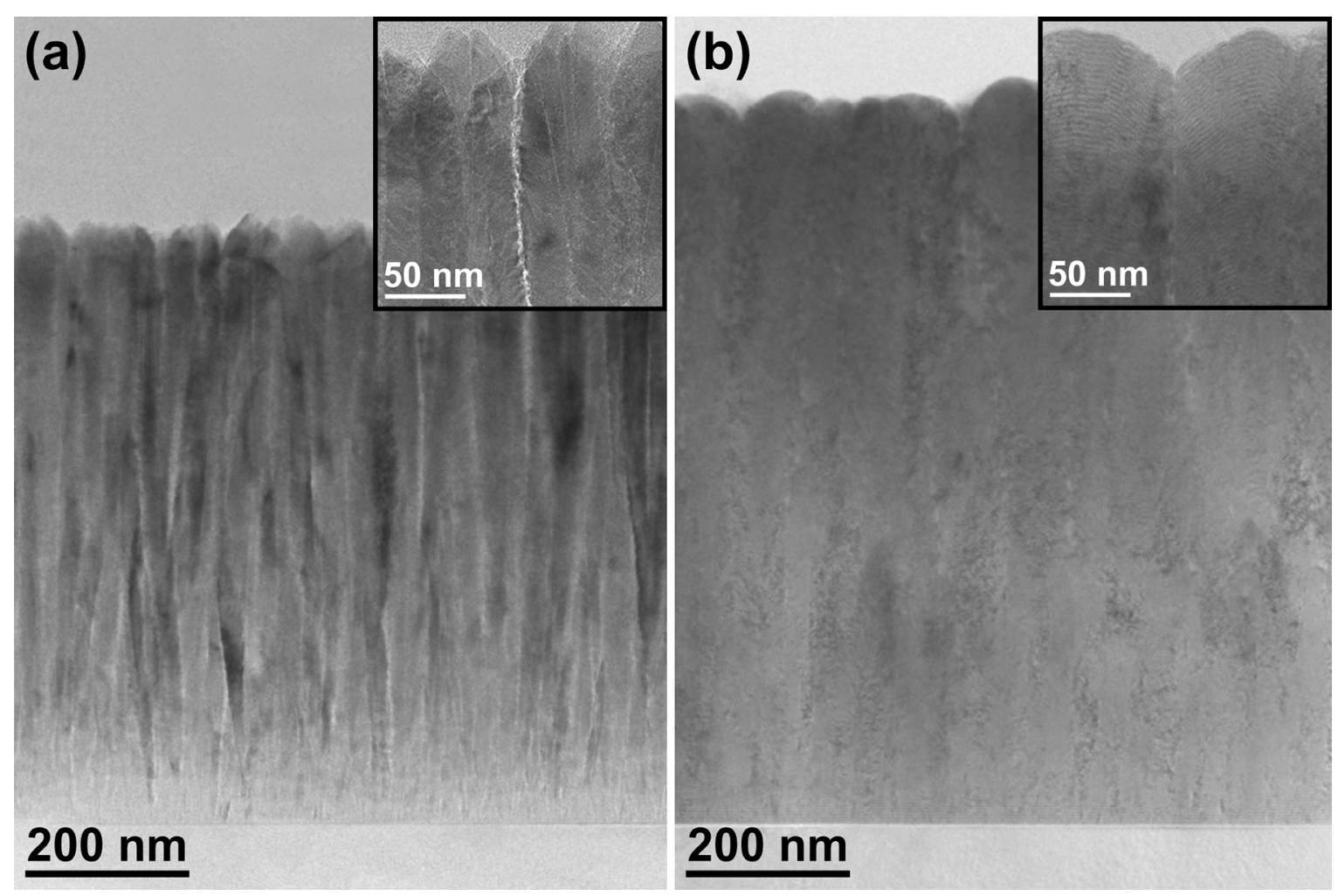

Fig. 6. Cross-sectional TEM images of (a) $\mathrm{Ti}_{0.58} \mathrm{Al}_{0.42} \mathrm{~N}$ and (b) $\mathrm{Ti}_{0.40} \mathrm{Al}_{0.27} \mathrm{~W}_{0.33} \mathrm{~N}$ films together with higher magnification insets of the top of the same samples in.

A cross-sectional Z-contrast lattice-resolution image of $\mathrm{Ti}_{0.40} \mathrm{Al}_{0.27} \mathrm{~W}_{0.33} \mathrm{~N}$ film is shown in Fig. 7, revealing a 3.6-nm-thick multilayer structure. Each layer is composed of 3.2-nm-thick bright contrast sublayers containing heavy W atoms and 0.4-nm-thick darker areas comprised predominantly TiAlN. The image also shows coherent lattice fringes extending across all nanolayers indicating local epitaxy within columns. 


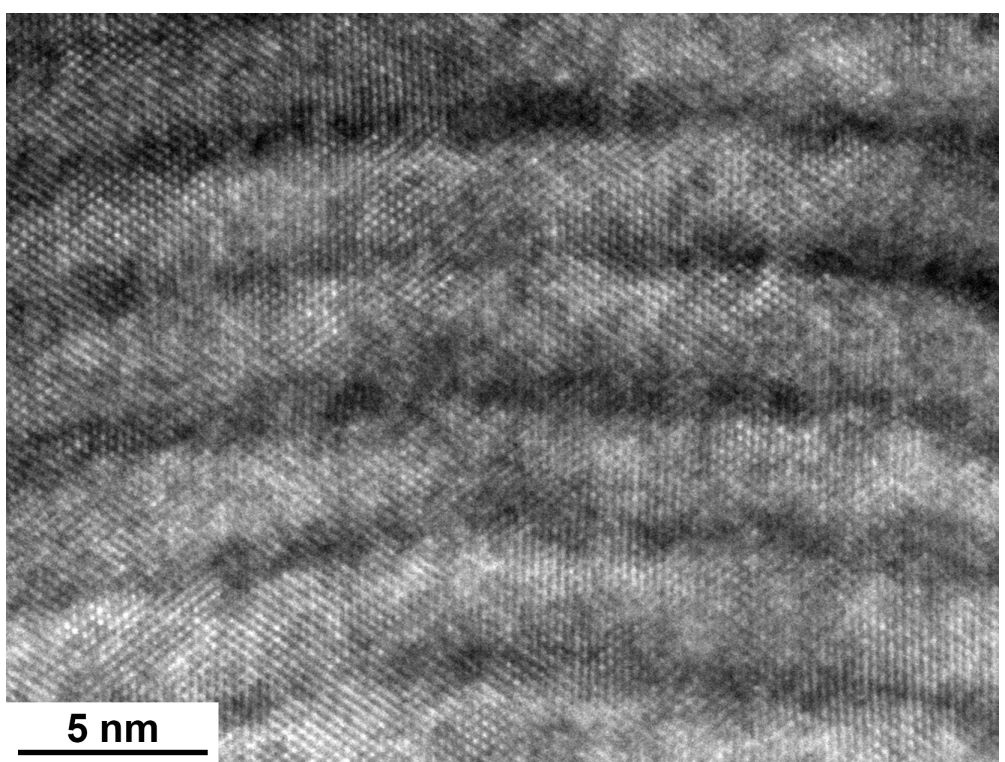

Fig. 7. STEM image from the upper part of $\mathrm{Ti}_{0.40} \mathrm{Al}_{0.27} \mathrm{~W}_{0.33} \mathrm{~N}$ sample. A selforganized nano-multilayer architecture can be observed in the film.

Ti 2p, Al 2p, N 1s, and W 4f XPS spectra obtained from $\operatorname{Ti}_{0.58} \mathrm{Al}_{0.42} \mathrm{~N}$ and $\mathrm{Ti}_{0.40} \mathrm{Al}_{0.27} \mathrm{~W}_{0.33} \mathrm{~N}$ films are shown in Fig. 8. The Ti 2p spectra (Fig. 8(a)) consist of a spin-orbit-split doublet $2 \mathrm{p}_{3 / 2}-2 \mathrm{p}_{1 / 2}$ with peaks at 455.3 and $461.1 \mathrm{eV}$, respectively. The peak positions are essentially the same for both films. There are satellite features on the high $\mathrm{BE}$ sides of the primary peaks, shifted by $\sim 2.7 \mathrm{eV}$, in agreement with previouslyreported XPS data recorded in-situ during growth of polycrystalline TiN layers. ${ }^{35-36}$ The origin of the satellite peaks is still unclear, suggestions include a decrease in the screening probability of the core hole created during photoionization of Ti $3 \mathrm{~d}$ electrons, ${ }^{37-38}$ and $t_{1 g} \rightarrow 2 t_{2 g}$ intraband transitions between occupied and unoccupied electron states near the Fermi level (shake-up events). ${ }^{39-40}$ The Al 2p spectra in Fig. 8(a) contain a single peak at $74.5 \mathrm{eV}$, which is assigned to $\mathrm{Al}$ atoms incorporated in $\mathrm{Ti}_{1-\mathrm{x}} \mathrm{Al}{ }_{\mathrm{x}} \mathrm{N}$, the peak position is the same for both films. The higher background in the case of the spectrum obtained from 
$\mathrm{Ti}_{0.40} \mathrm{Al}_{0.27} \mathrm{~W}_{0.33} \mathrm{~N}$ film is due to a broad W 5 s signal. ${ }^{41}$ In contrast, the N 1s spectra (Fig. 8(c)) from the W-containing layer is shifted by $\sim 0.4 \mathrm{eV}$, from $397.1 \mathrm{eV}$ for $\mathrm{Ti}_{0.58} \mathrm{Al}_{0.42} \mathrm{~N}$ film to $397.5 \mathrm{eV}$ for $\mathrm{Ti}_{0.40} \mathrm{Al}_{0.27} \mathrm{~W}_{0.33} \mathrm{~N}$. This is due to a significant contribution to the latter spectrum from $\mathrm{N}$ incorporated in WN layers, in agreement with previous XPS analyses of WN, which revealed the $\mathrm{N} 1$ s peak at $397.9 \mathrm{eV} .{ }^{28} \mathrm{~W}$ 4f spectra shown in Fig. 8(d) show a $4 \mathrm{f}_{7 / 2}-4 \mathrm{f}_{5 / 2}$ doublet in the case of $\mathrm{Ti}_{0.40} \mathrm{Al}_{0.27} \mathrm{~W}_{0.33} \mathrm{~N}$ which is superimposed on a lower-intensity Ti $3 \mathrm{p}$ peak. The latter is clearly seen in the case of the $\mathrm{Ti}_{0.58} \mathrm{Al}_{0.42} \mathrm{~N}$ reference sample which does not contain $\mathrm{W}$. The $4 \mathrm{f}_{7 / 2}-4 \mathrm{f}_{5 / 2}$ doublet is symmetric toward the low BE side and the spectrum can be fitted with two pairs of peaks, one for metallic $\mathrm{W}$ and one for $\mathrm{WN}$ with the $4 \mathrm{f}_{7 / 2}$ components at 31.4 and $32.2 \mathrm{eV}$, respectively.
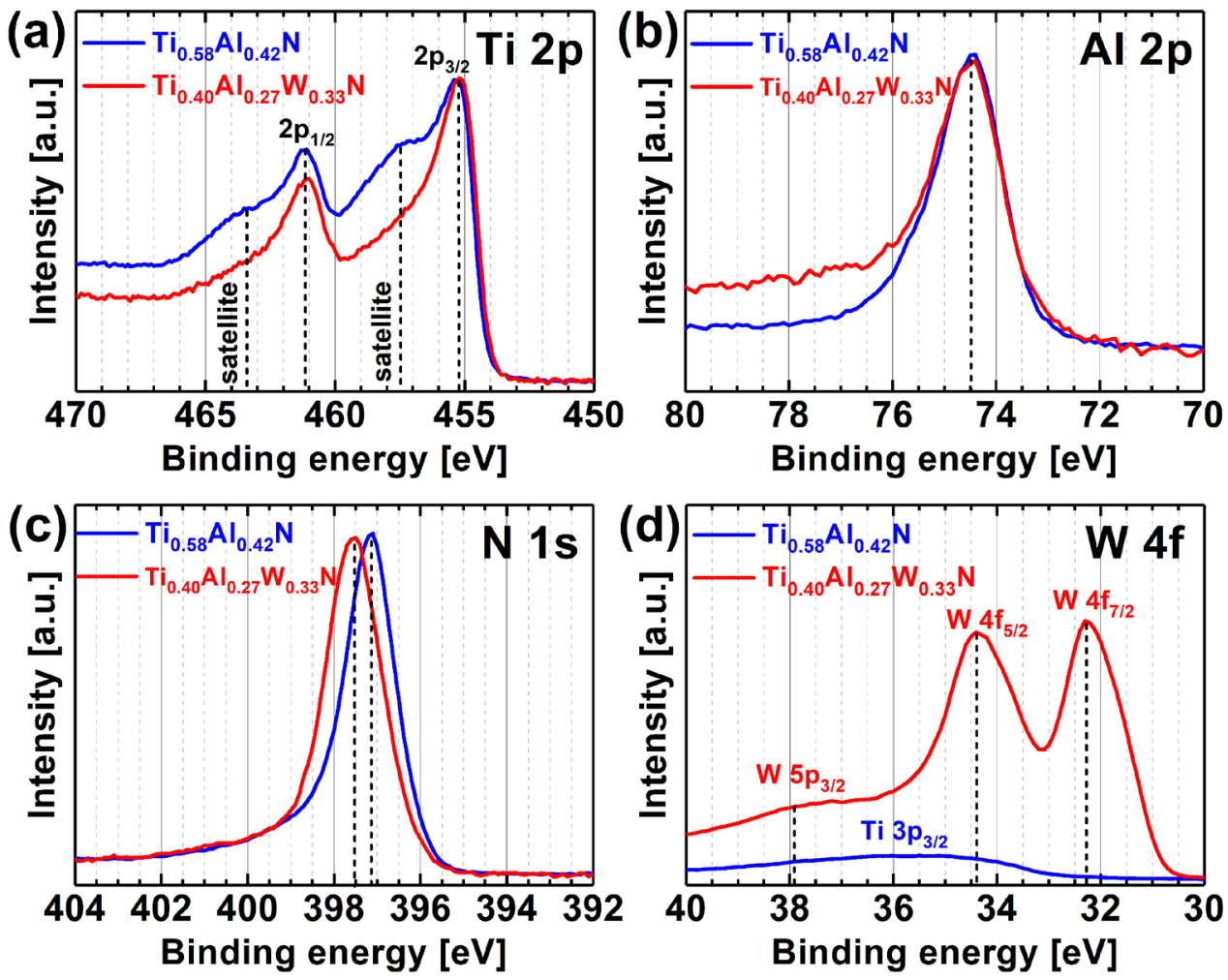

Fig. 8. (a) Ti 2p, (b) Al 2p, (c) N 1s, and (d) W 4f XPS spectra of $\mathrm{Ti}_{0.58} \mathrm{Al}_{0.42} \mathrm{~N}$ and $\mathrm{Ti}_{0.40} \mathrm{Al}_{0.27} \mathrm{~W}_{0.33} \mathrm{~N}$ films. 
The mechanical properties of the reference $\mathrm{Ti}_{0.58} \mathrm{Al}_{0.42} \mathrm{~N}$ films are significantly improved by $\mathrm{W}^{+}$ion bombardment. The results are shown in Table 2. Nanoindentation hardness increases from 10.9 to $23.1 \mathrm{GPa}$ for the $\mathrm{Ti}_{0.40} \mathrm{Al}_{0.27} \mathrm{~W}_{0.33} \mathrm{~N}$ film, while the elastic modulus increases from 272 to $378 \mathrm{GPa}$. The effect is a consequence of the reduced porosity combined with the presence of nanolayers. The $H^{3} / E^{2}$ ratio, a qualitative indication of wear resistance, ${ }^{42}$ increases from 0.02 for $\mathrm{Ti}_{0.58} \mathrm{Al}_{0.42} \mathrm{~N}$ to $0.09 \mathrm{GPa}$ for $\mathrm{Ti}_{0.40} \mathrm{Al}_{0.27} \mathrm{~W}_{0.33} \mathrm{~N}$.

TABLE 2. Indentation hardness $H$, elastic modulus $E$, and $H^{3} / E^{2}$ ratios of $\mathrm{Ti}_{0.58} \mathrm{Al}_{0.42} \mathrm{~N}$ and $\mathrm{Ti}_{0.40} \mathrm{Al}_{0.27} \mathrm{~W}_{0.33} \mathrm{~N}$ films.

\begin{tabular}{llcc}
\hline \hline Samples & $H[\mathrm{GPa}]$ & $E[\mathrm{GPa}]$ & $H^{3} / E^{2}[\mathrm{GPa}]$ \\
\hline $\mathrm{Ti}_{0.58} \mathrm{Al}_{0.42} \mathrm{~N}$ & 10.9 & 272 & 0.02 \\
$\mathrm{Ti}_{0.40} \mathrm{Al}_{0.27} \mathrm{~W}_{0.33} \mathrm{~N}$ & 23.1 & 378 & 0.09 \\
\hline
\end{tabular}

\section{B. Discussion}

In previous experiments with Ti-DCMS/Ta-HiPIMS $\mathrm{Ti}_{0.92} \mathrm{Ta}_{0.08} \mathrm{~N}$ and TaHiPIMS/Ti-DCMS/Al-DCMS $\mathrm{Ti}_{0.41} \mathrm{Al}_{0.51} \mathrm{Ta}_{0.08} \mathrm{~N}$ growth performed in a stationary multitarget configuration, ${ }^{9-10}$ irradiation by heavy-metal ions from the HiPIMS target was very effective in densifying the growing film in the absence of substrate heating. This was primarily due to the fact that the zone of intense near-surface intermixing of 0.16-0.19 nm, determined by the collision-cascade range of the $160 \mathrm{eV} \mathrm{Ta}^{+}$ions, was much larger than the DCMS layer thickness deposited between successive HiPIMS pulses. Thus, under such conditions both the primary $\mathrm{Ta}^{+}$metal ions and the recoiled $\mathrm{Ta}$ lattice atoms penetrate deep into the near-surface region to dynamically fill residual vacancies resulting 
from very-low-temperature growth with no external substrate heating. Given that $\mathrm{Ta}$ atoms are $8 \%$ of the metal constituents in the films, we can obtain an estimate for the energy per deposited metal atom, $E_{D}$, assuming that the fraction of ionized Ta species is between $30-80 \%$, i.e., in the range typically cited in the HiPIMS literature. ${ }^{43-44}$ Under the conditions of Refs. 9 and 10, dense $\mathrm{Ti}_{0.92} \mathrm{Ta}_{0.08} \mathrm{~N}$ and $\mathrm{Ti}_{0.41} \mathrm{Al}_{0.51} \mathrm{Ta}_{0.08} \mathrm{~N}$ films were obtained with $E_{D}$ values of $4-10 \mathrm{eV} /$ metal atom.

In the present experiments, the situation is different. Instead of continuous film deposition, the substrate rotation results in deposition from each DCMS target to a thickness of a few nm before the film is exposed to the intense $\mathrm{W}^{+}$ion flux from the adjacent HiPIMS target. This, together with target-substrate separation varying continuously, make the film densification process much more challenging. Thus, we selected $\mathrm{W}^{+}$instead of $\mathrm{Ta}^{+}$to further enhance sputter gas rarefaction, ${ }^{15}$ as both have very close atomic numbers, but the former target has lower reactivity towards $\mathrm{N}_{2}$, which allows for (i) better separation of metal and gas ion fluxes at the substrate, and (ii) high sputtering rate and, hence, high metal-gas collision rate. A multilayer structure is obtained in $\mathrm{Ti}_{0.40} \mathrm{Al}_{0.27} \mathrm{~W}_{0.33} \mathrm{~N}$ films deposited with substrate rotation, as evidenced by mass-contrast in $\mathrm{W}$-rich areas and is caused by the substrate rotation during film growth such that two periods in the image of Fig. 7 correspond to one full revolution of the substrate. $\mathrm{W}^{+}$ions are incorporated into the TiAlN layers when exposed to the $\mathrm{W}$ targets and provide a template for further growth of the W-rich film during the time substrate is facing HiPIMS magnetrons.

In addition, a high substrate bias $V_{s}=-500 \mathrm{~V}$ is used in order to increase the $\mathrm{W}^{+}$ ion penetration range. A TiAlN layer deposited during a substrate pass under a TiAl 
target is then subjected to $\mathrm{W}^{+}$ion irradiation as it passes in front of the adjacent $\mathrm{W}$ target. The thickness of the TiAlN layer deposited per pass under a TiAl target is $\sim 3.0 \mathrm{~nm}$ based on deposition rate calibrations. The projected range of $500-\mathrm{eV}-\mathrm{W}^{+}$ions in $\mathrm{Ti}_{0.58} \mathrm{Al}_{0.42} \mathrm{~N}$ is $\sim 2.5 \mathrm{~nm}$ with a straggle of $0.4 \mathrm{~nm}$. As $\mathrm{W}$ is implanted the projected ranges drops to $\sim 1.9$ $\mathrm{nm}$ with straggling of $0.7 \mathrm{~nm}$ and the total thickness of the nano period layer increases to $3.6 \mathrm{~nm}$. Thus, a two-layer structure is formed, a thin $(\sim 0.4 \mathrm{~nm}) \mathrm{W}$-deficient and a W-rich layer of $3.2 \mathrm{~nm}$. The intermittent $\mathrm{W}^{+}$irradiation creates a large number of recoils to ensure film densification.

From the RBS areal density $\left(N_{t}\right)$ of the $\mathrm{Al}$ and $\mathrm{Ti}$ atoms for the $\mathrm{Ti}_{0.58} \mathrm{Al}_{0.42} \mathrm{~N}$ vs. the thickness of the films $t$, we calculate the density of the metal atoms $-\mathrm{N}=4.25 \times 10^{22}$ at $/ \mathrm{cm}^{3}$. The ideal bulk density of metal atoms comprising a $\mathrm{B} 1-\mathrm{NaCl}$ transition-metal nitride (four metal atoms per unit cell) with a lattice constant of $4.20 \AA$ is $5.40 \times 10^{22}$ at $/ \mathrm{cm}^{3}$. Thus, the $\mathrm{Ti}_{0.58} \mathrm{Al}_{0.42} \mathrm{~N}$ film density is $73 \%$, a similar estimate for $\mathrm{Ti}_{0.40} \mathrm{Al}_{0.27} \mathrm{~W}_{0.33} \mathrm{~N}$ films yields a density of $95 \%$, which represents a $30 \%$ increase in film density.

The good matching of the collision cascade range, predicted by TRIM calculations, with the thickness of the W-rich layer indicates that the latter can be controlled by varying the amplitude of the synchronous bias pulse. For example, TRIM simulations indicate that ion energy of $100 \mathrm{eV}$ would yield approximately equal thicknesses of both nanolayers, while energy of $\sim 600-650 \mathrm{eV}$ would eliminate the Wdeficient layer and produce a nearly uniform TiAlWN film.

Another point of discussion is the amount of $\mathrm{W}^{+}$ion needed to achieve densification. Under the conditions of our experiments, $\mathrm{W}^{+}$irradiation yields energy per 
deposited atom values $E_{D}$ (estimated in the way described above) in the range of 50-130 $\mathrm{eV} /$ metal atom. These values are an order of magnitude higher than what is sufficient to produce dense $\mathrm{Ti}_{0.92} \mathrm{Ta}_{0.08} \mathrm{~N}$ and $\mathrm{Ti}_{0.41} \mathrm{Al}_{0.51} \mathrm{Ta}_{0.08} \mathrm{~N}$ films. ${ }^{9-10}$ This fact suggests that it is possible to reduce the $\mathrm{W}^{+}$ion flux by tuning the peak target current during the HiPIMS discharge and thus achieving dense films even with significantly lower content of W.

The present work indicates the succession of growing dense, hard, and stress-free refractory thin films with no external heating, by using $\mathrm{W}^{+}$irradiation. Since a low growth temperature is used for the $\operatorname{Ti}_{0.58} \mathrm{Al}_{0.42} \mathrm{~N}$ deposition, nonsufficient adatom mobilities produce a high porosity and thus make film softer, i.e. $H=10.9 \mathrm{GPa}$. Ion bombardment with high energy and Ar trapping favors the precipitation of wurtzitestructure AlN $(w-A I N) .{ }^{12,} 26$ These negative effects of noble gas ion bombardment are eliminated during film growth with $\mathrm{W}^{+}$irradiation. First, high mass of $\mathrm{W}^{+}$ions together with low reactivity with $\mathrm{N}_{2}$ helps to enhance gas rarefaction, especially for Ar, as evidenced by ion mass spectrometry results collected during W-HiPIMS at the substrate position. Second, in contrast to conventional DCMS processing, the high-amplitude bias is applied with low duty cycle which reduces resputtering effects. Moreover, the lowtemperature deposition produced high porosity provides the ability to release a high intrinsic stress when exposed to a high-energy $\mathrm{W}^{+}$ion irradiation. Furthermore, it is important to note that no signals corresponding to $w$-AlN are found in the XRD patterns (Fig. 5). All of the above factors help achieve $30 \%$ increase in film density and obtain superior mechanical properties $(H=23.1 \mathrm{GPa}, E=378 \mathrm{GPa})$ together with low stress ($1.2 \mathrm{GPa})$ in low- $T_{s}$-deposition of $\mathrm{Ti}_{0.40} \mathrm{Al}_{0.27} \mathrm{~W}_{0.33} \mathrm{~N}$ films performed with rotating substrates. 


\section{IV.SUMMARY AND CONCLUSIONS}

Cubic-structure $\mathrm{Ti}_{0.58} \mathrm{Al}_{0.42} \mathrm{~N}$ and $\mathrm{Ti}_{0.40} \mathrm{Al}_{0.27} \mathrm{~W}_{0.33} \mathrm{~N}$ films with no external substrate heating are deposited in an industrial system with substrate rotation. A comparative investigation on elemental compositions, microstructure, and mechanical properties of films against $\mathrm{W}^{+}$ion irradiation is conducted. $\mathrm{W}^{+}$ion irradiation is generated by $110-\mu \mathrm{s}-\mathrm{HiPIMS}$ pulses and selectively accelerated to reach $\sim 500 \mathrm{eV}$ at the substrate. The results show that $\mathrm{W}^{+}$ion irradiation powered by HiPIMS with synchronized bias effectively densifies the $\mathrm{Ti}_{0.40} \mathrm{Al}_{0.27} \mathrm{~W}_{0.33} \mathrm{~N}$ films, whereas a porous microstructure evolves in $\mathrm{Ti}_{0.58} \mathrm{Al}_{0.42} \mathrm{~N}$. In addition, the highly-energetic $\mathrm{W}^{+}$ion bombardment has only a slight impact on residual stress of $\mathrm{Ti}_{0.40} \mathrm{Al}_{0.27} \mathrm{~W}_{0.33} \mathrm{~N}$ films which is essentially the same as for the $\mathrm{Ti}_{0.58} \mathrm{Al}_{0.42} \mathrm{~N}$ layers, and amounts to -1.1 and $-1.2 \mathrm{GPa}$, respectively. The latter advantage is due to the bias synchronization to the $\mathrm{W}^{+}$-rich portions of HiPIMS pulses which enables us to lower concentrations of interstitial Ar known for increasing residual stresses. $\mathrm{Ti}_{0.40} \mathrm{Al}_{0.27} \mathrm{~W}_{0.33} \mathrm{~N}$ exhibits $30 \%$ increase in film density and mechanical properties $H=23.1 \mathrm{GPa}$ and $E=378 \mathrm{GPa}$, which are typical for layers grown at high temperatures. The here demonstrated new processing route allows to grow high-quality ceramic layers at temperatures below $150{ }^{\circ} \mathrm{C}$, thus expands the application range to temperature-sensitive substrates.

\section{ACKNOWLEDGMENTS}

The authors most gratefully acknowledge the financial support of the Knut and Alice Wallenberg Foundation Scholar Grant KAW2016.0358, the VINN Excellence Center Functional Nanoscale Materials (FunMat-2) Grant 2016-05156, the Swedish Research Council VR Grant 2018-03957, the VINNOVA Grant 2018-04290, the Åforsk 
Foundation Grant 16-359, and Carl Tryggers Stiftelse Contract CTS 17:166. Wu and Wang thank the support from the National Natural Science Foundation of China (51901048 and 51875109) and the Natural Science Foundation of Guangdong Province (2018A030310546 and 2019A1515012234) as well.

\section{References}

${ }^{1}$ J.L. Vossen, W. Kern, W. Kern, Thin film processes II (Gulf Professional Publishing, 1991).

${ }^{2}$ I. Petrov, P. Barna, L. Hultman, J. Greene, J. Vac. Sci. Technol. A 21, S117 (2003).

${ }^{3}$ G.I. Grigorov, I.N. Martev, M.V. Stoyanova, J.L. Vignes, J.P. Langeron, Thin Solid Films 198, 169 (1991).

${ }^{4}$ L. Bárdoš, H. Baránková, Surf. Coat. Technol. 146, 463 (2001).

${ }^{5}$ A. Anders, Thin Solid Films 518, 4087 (2010).

${ }^{6}$ G. Håkansson, J.E. Sundgren, D. McIntyre, J.E. Greene, W.D. Münz, Thin Solid Films 153, 55 (1987).

${ }^{7}$ D. Gall, I. Petrov, N. Hellgren, L. Hultman, J. Sundgren, J. Greene, J. Appl. Phys. 84, 6034 (1998).

${ }^{8}$ A. Hörling, L. Hultman, M. Odén, J. Sjölén, L. Karlsson, Surf. Coat. Technol. 191, 384 (2005).

${ }^{9}$ G. Greczynski, J. Lu, S. Bolz, W. Kölker, C. Schiffers, O. Lemmer, I. Petrov, J.E. Greene, L. Hultman, J. Vac. Sci. Technol. A 32, 041515 (2014).

${ }^{10}$ H. Fager, O. Tengstrand, J. Lu, S. Bolz, B. Mesic, W. Kölker, C. Schiffers, O. Lemmer, J.E. Greene, L. Hultman, J. Appl. Phys. 121, 171902 (2017). 
${ }^{11}$ G. Greczynski, I. Petrov, J.E. Greene, L. Hultman, J. Vac. Sci. Technol. A 37, 060801 (2019).

${ }^{12}$ G. Greczynski, J. Lu, J. Jensen, I. Petrov, J.E. Greene, S. Bolz, W. Kölker, C. Schiffers, O. Lemmer, L. Hultman, J. Vac. Sci. Technol. A 30, 061504 (2012).

${ }^{13}$ M. Mühlbacher, G. Greczynski, B. Sartory, N. Schalk, J. Lu, I. Petrov, J.E. Greene, L. Hultman, C. Mitterer, Sci. Rep. 8, 5360 (2018).

${ }^{14}$ V. Tiron, I.L. Velicu, C. Porosnicu, I. Burducea, P. Dinca, P. Malinský, Appl. Surf. Sci. 416, 878 (2017).

${ }^{15}$ G. Greczynski, I. Zhirkov, I. Petrov, J.E. Greene, J. Rosen, J. Vac. Sci. Technol. A 36, 020602 (2018).

${ }^{16}$ T. Reeswinkel, D.G. Sangiovanni, V. Chirita, L. Hultman, J.M. Schneider, Surf. Coat. Technol. 205, 4821 (2011).

${ }^{17}$ D.G. Sangiovanni, V. Chirita, L. Hultman, Thin Solid Films 520, 4080 (2012).

${ }^{18}$ S.A. Glatz, H. Bolvardi, S. Kolozsvári, C.M. Koller, H. Riedl, P.H. Mayrhofer, Surf. Coat. Technol. 332, 275 (2017).

${ }^{19}$ J. Bohlmark, M. Lattemann, J. Gudmundsson, A. Ehiasarian, Y.A. Gonzalvo, N. Brenning, U. Helmersson, Thin Solid Films 515, 1522 (2006).

${ }^{20}$ G. Greczynski, L. Hultman, Vacuum 84, 1159 (2010).

${ }^{21}$ G. Greczynski, L. Hultman, Prog. Mater. Sci. 107, 100591 (2019).

${ }^{22}$ G. Greczynski, D. Primetzhofer, J. Lu, L. Hultman, Appl. Surf. Sci. 396, 347 (2017).

${ }^{23}$ G. Greczynski, D. Primetzhofer, L. Hultman, Appl. Surf. Sci. 436, 102 (2018).

${ }^{24}$ E. Lewin, J. Counsell, J. Patscheider, Appl. Surf. Sci. 442, 487 (2018).

${ }^{25}$ K. Sato, N. Ichimiya, A. Kondo, Y. Tanaka, Surf. Coat. Technol. 163, 135 (2003). 
${ }^{26}$ G. Greczynski, J. Lu, M. Johansson, J. Jensen, I. Petrov, J.E. Greene, L. Hultman, Surf. Coat. Technol. 206, 4202 (2012).

${ }^{27}$ W.C. Oliver, G.M. Pharr, J. Mater. Res. 7, 1564 (1992).

${ }^{28}$ P. Sigmund, J. Vac. Sci. Technol. 17, 396 (1980).

${ }^{29}$ M.W. Thompson, Phys. Rep. 69, 335 (1981).

${ }^{30}$ J. Gudmundsson, N. Brenning, D. Lundin, U. Helmersson, J. Vac. Sci. Technol. A 30, 030801 (2012).

${ }^{31}$ A. Anders, S. Anders, M.A. Gundersen, A.M. Martsinovskii, IEEE Trans. Plasma Sci. 23, 275 (1995).

${ }^{32}$ A. Anders, J. Andersson, A. Ehiasarian, J. Appl. Phys. 102, 113303 (2007).

${ }^{33}$ M. Chase, NIST-JANAF Thermochemical Tables (J. Phys. Chem. Ref. Data Monogr. 9) (Woodbury, NY: AIP, 1998).

${ }^{34}$ W.M. Haynes, CRC handbook of chemistry and physics (CRC press, 2014).

${ }^{35}$ I. Bertoti, M. Mohai, J. Sullivan, S. Saied, Surf. Interface Anal. 21, 467 (1994).

${ }^{36}$ A. Arranz, C. Palacio, Surf. Sci. 600, 2510 (2006).

${ }^{37}$ L. Porte, L. Roux, J. Hanus, Phys. Rev. B 28, 3214 (1983).

${ }^{38}$ J. Patscheider, N. Hellgren, R.T. Haasch, I. Petrov, J. Greene, Phys. Rev. B 83, 125124 (2011).

${ }^{39}$ S. Hofmann, J. Electron Spectrosc. Relat. Phenom. 56, 85 (1991).

${ }^{40}$ D. Jaeger, J. Patscheider, J. Electron Spectrosc. Relat. Phenom. 185, 523 (2012).

${ }^{41}$ J.F. Moulder, W. Stickle, P. Sobol, K. Bomben, Handbook of X-ray Photoelectron Spectroscopy (Perkin-Elmer Corporation, Eden Prairie, MN, USA, 1992).

${ }^{42}$ A. Leyland, A. Matthews, Wear 246, 1 (2000). 
${ }^{43}$ K. Sarakinos, J. Alami, S. Konstantinidis, Surf. Coat. Technol. 204, 1661 (2010).

${ }^{44}$ A. Anders, J. Appl. Phys. 121, 171101 (2017). 
